\title{
A FESTA E A MAGIA \\ NAS XILOGRAVURAS DE J. BORGES
}

Laura Bitarelli Reboulet (Paris III - Sorbonne Nouvelle)

Este texto analisa as obras em xilogravura de José Francisco Borges, conhecido como J. Borges, um dos artistas populares mais renomados da América Latina, que descreve o universo da cultura popular do Nordeste brasileiro. Observaremos quatro de suas obras, que têm como representação determinadas temáticas do imaginário da região: as festas, os costumes sociais, os mitos e as narrativas fantásticas.

CULTURA POPULAR, IMAGINÁRIO, IDENTIDADE, XILOGRAVURA, J. BORGES.

REBOULET, Laura Bitarelli. A festa e a magia nas xilogravuras de J. Borges. Textos escolhidos de cultura e arte populares, Rio de Janeiro, v.9, n.2, p. 91-105, nov. 2012. 


\section{PARTY AND MAGIC IN THE WOODCUTS OF J. BORGES}

Laura Bitarelli Reboulet (Paris III - Sorbonne Nouvelle)

This text analyzes the woodcut work of José Francisco Borges, known as J. Borges, one of the most renowned folk artists from Latin America, and who describes the universe of popular culture in Northeast Brazil. We analyze four of his works, which are representative of certain thematic imagery from that region: the festivals, social customs, myths and fantastic narratives.

POPULAR CULTURE, IMAGINARY, IDENTITY, WOODCUT, J. BORGES.

REBOULET, Laura Bitarelli. A festa e a magia nas xilogravuras de J. Borges. Textos escolhidos de cultura e arte populares, Rio de Janeiro, v.9, n.2, p. 91-105, nov. 2012. 
A iconografia de J. Borges pertence aos domínios da denominada pintura naïf. Nessa elaboração visual notamos a ausência dos aspectos formais acadêmicos, como a composição, a perspectiva e o respeito às cores reais. 0 que caracteriza essa arte são as cores vivas, imaginação criativa, espontânea e informal, e técnica aparentemente rudimentar. Ela revela valores plásticos e figurativos extremamente ricos, tanto na utilização de cores fortes como na organização dos espaços que rompem com a perspectiva clássica, revelando um imaginário lúdico e poético que se encontra nos domínios da pintura popular ou dita primitiva, elaborada geralmente, por artistas autodidatas e sem formação acadêmica.

O termo naïf foi utilizado pela primeira vez no século XIX para qualificar as obras do pintor Douanier Rousseau, que pintava fora das normas acadêmicas. De fato, contrariamente aos princípios plásticos edificados pelo rigor acadêmico, o artista naïf não diminui o tamanho dos objetos, não atenua as cores e não diminui a precisão dos detalhes proporcionalmente à distância na superfície da obra. A expressão artística naïf se caracteriza igualmente por representação figurativa de temas populares (paisagens camponesas, cenas da vida cotidiana, costumes folclóricos, animais domésticos ou selvagens, representação de temas fantásticos e religiosos). Autodidata, o artista naïf inventa suas próprias técnicas.

No que se refere à técnica de criação, as obras desse gênero se caracterizam pela exuberância das formas e das cores, das relações de escala e de perspectivas inabituais, assim como abundância de detalhes. Cabe registrar que, em seu poema "Au Cabaret Vert", publicado em 1870, Arthur Rimbaud já emprega o termo para designar representações pictóricas consideradas desajeitadas: "Contente, estiquei as pernas embaixo da mesa: eu contemplava os temas muito ingênuos da tapeçaria". ${ }^{1}$

Segundo Mário Pedrosa, as manifestações artísticas denominadas primeiras ou primitivas serviram de inspiração para muitas experimentações que marcaram profundamente a pintura moderna europeia entre o final do século XIX e o início do XX. Em grande parte, os vanguardistas europeus foram buscar novos modelos figurativos nos procedimentos da chamada arte primitiva.

Nesse sentido, Pedrosa (1979, p. 119-145) afirma que a arte europeia toma novos caminhos: "Agora, na sua independência em relação ao mundo exterior, na sua hostilidade à representação naturalista, na sua tendência à pura realização criadora, isto é, ao estilo, ela instintivamente se aproxima da arte dos povos estranhos ou alheios ao ideal naturalista grego". Esta é a trajetória apontada por Mario de Micheli (1991, p. 55): “Tudo o que era 'bárbaro', tudo o 
que não era Grécia clássica ou Renascença, ou tradição a ela relacionada atraía com uma insólita violência". O autor ressalta que os artistas se voltavam para o arcaico, o bárbaro, o folclore camponês, as civilizações pré-clássicas, tendo como denominador comum a oposição à arte oficial ou o impulso da evasão.

No âmbito das ciências sociais e da teoria da arte há diversos significados para o conceito de "primitivo". As primeiras indicações do uso do termo remontam ao século XVI referindo-se aos pintores e escultores que viveram nos séculos XIII e XV, período imediatamente anterior àquele conhecido como Alta Renascença. No século XX, o termo passa a designar, na trilha de estudos antropológicos, a realização artística nos domínios das artes visuais que, de algum modo, estava isolada e independente da cultura vigente, em territórios afastados da sociedade europeia. A chamada arte primitiva revela inobservância dos padrões acadêmicos através de seus valores plásticos considerados ingênuos e simples. Dito de outro modo, trata-se de uma quebra dos rigores e dos protocolos da arte edificada pelos padrões dominantes do mundo ocidental, originários da herança greco-romana. Em última instância, essa visão profundamente eurocêntrica considera primitiva toda manifestação artística portadora de valores estranhos ou diversos dos vigentes nas sociedades ocidentais economicamente avançadas.

\section{O ARTISTA J. BORGES}

No ideário do modernismo brasileiro, a identidade nacional autêntica se encontrava então na cultura popular e regional. É por isso que a junção de arte e folclore vai ocorrer de maneira muito intensa em praticamente todos os campos artísticos brasileiros: na pintura de Tarsila do Amaral e de Di Cavalcanti, em que vemos um Brasil lúdico e mítico, enraizado nas lendas, nas narrativas populares, na simplicidade da vida cotidiana, nas festas regionais, nos folguedos carnavalescos e em sua diversidade étnica; em Macunaíma, de Mário de Andrade, em que o personagem indígena representa o multiculturalismo do povo brasileiro; na música de Villa-Lobos, em que são incorporados elementos das canções folclóricas, populares e indígenas. Essas temáticas terão prosseguimento nos relatos sobre a simplicidade da vida cotidiana e as exigências do mundo do trabalho retratadas por Portinari na década de $1930 .{ }^{2}$

J. Borges (Figura 1) também aborda esse contexto, pois, em suas histórias, ele representa diferentes aspectos do universo cultural e popular do Nordeste; ao contrário, porém, dos intelectuais modernistas, ele próprio é originário do meio que descreve. Nascido em Pernambuco na cidade de Bezerros em 1935, filho de agricultores, ele trabalha desde cedo ao lado de 


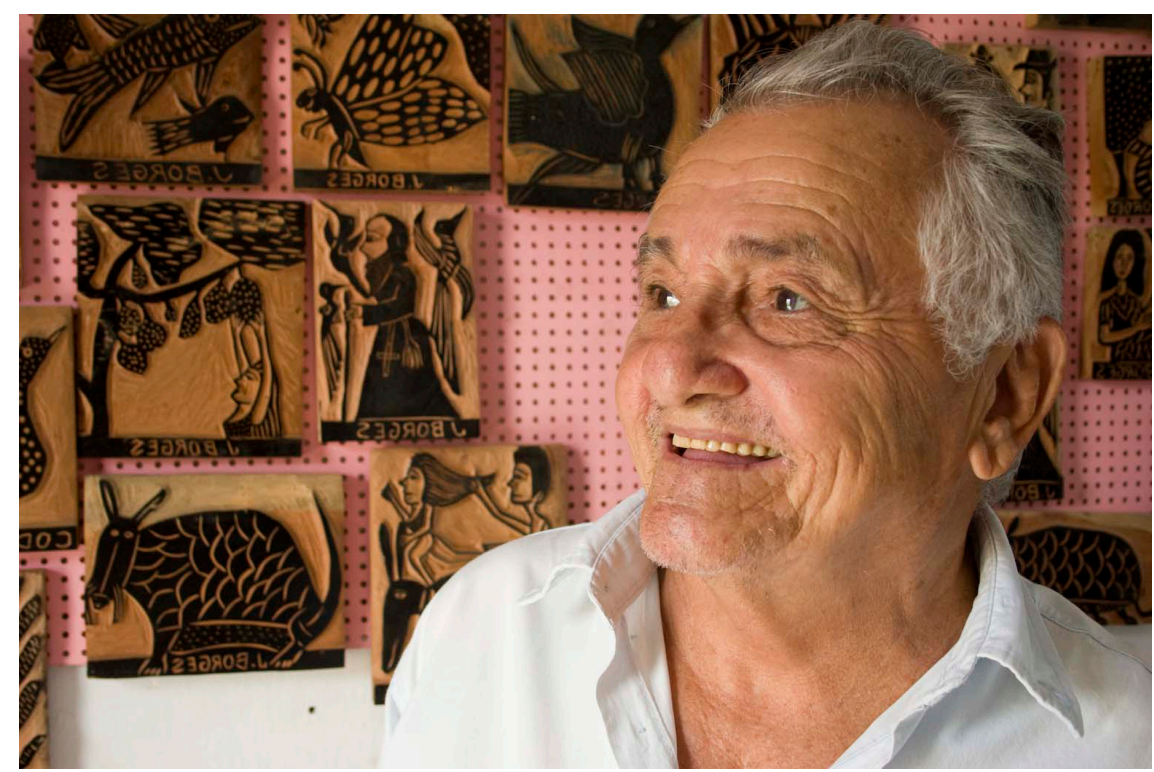

Figura 1: J. Borges em seu ateliê em Bezerros Foto: Francisco Moreira da Costa

seu pai. Só frequenta a escola alguns meses, o necessário para aprender a ler e escrever. Aos 20 anos, torna-se vendedor e declamador de folhetos, percorrendo, assim, as feiras e as festas populares do Nordeste com sua maleta e seu alto-falante. A literatura de cordel mudará então sua vida. Em 1964, consegue publicar seu primeiro folheto: O Encontro de dois Vaqueiros no Sertão de Petrolina, vendendo mais de cinco mil exemplares em apenas dois meses. Isso permitirá a publicação de seu segundo trabalho, agora ilustrado por ele. 0 vendedor de folhetos se torna poeta, gravurista e vendedor ambulante de sua própria produção. Contribuiu muito para sua valorização a descoberta de seu trabalho por parte do escritor e dramaturgo Ariano Suassuna.

A partir de 1970, J. Borges começou a receber pedidos para ampliar e vender suas xilogravuras e, em 1972, sua primeira exposição acontece no Rio de Janeiro. Em pouco tempo, seus trabalhos participavam de mostras na França, Alemanha, Suíça, Itália, Venezuela e Cuba. ${ }^{3}$

O cordel chegou ao Brasil com os colonizadores portugueses e conheceu intenso sucesso popular no final do século XIX, principalmente no Nordeste. A maioria dos autores é originária do sertão nos estados da Bahia, Pernambuco e Piauí, nos quais se concentram algumas das cidades com maiores índices de desigualdade social do país. Segundo o fotogravurista Pascal Baneux, o sertão é visto em todo o Brasil como no man's land, um lugar despovoado, de uma 


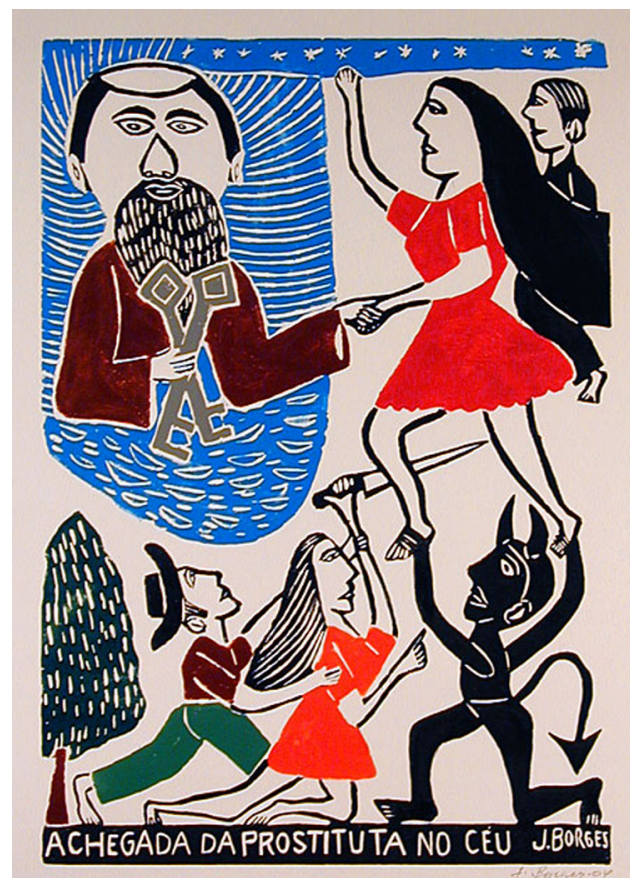

Figura 2: J. Borges, $A$ chegada da prostituta no Céu, 1976, xilogravura

zona inospitaleira, pobre e sem lei. Baneux explica que se fala de uma cultura popular no sertão porque ela se criou em torno de uma comunidade camponesa, muito pouco escolarizada e com forte desejo de inventar uma expressão, uma linguagem coletiva e específica (BANEUX, 2005, p. 17).

A oralidade, vetor dessa comunidade semianalfabeta fez com que o cordel fosse desenvolvido e distribuído sistematicamente na sociedade rural. Ele era sua fonte de informação e de entretenimento. Destinados à leitura pública por um contador ambulante, que era geralmente o autor, os textos de cordel são muitas vezes dominados por anedotas e brincadeiras. É uma poesia marcada por símbolos e jogos de linguagem, muitas vezes de difícil compreensão por estrangeiros. O nome tem origem na forma como os cordéis eram tradicionalmente expostos nas feiras europeias, pendurados em cordas ou barbantes. Essa prática, no entanto, não se perpetuou no Brasil e é por isso que, no meio popular, ele é mais conhecido como folheto.

As capas dos cordéis são ilustradas por uma xilogravura. De origem chinesa, a xilogravura ou gravura na madeira é o mais antigo processo de reprodução de imagem. Na Idade Média, na Europa, ela imprimia as representações religiosas. No início, tinha função secundária na ilustração dos cordéis. No Brasil, a fotografia, que era muito utilizada nas capas dos cordéis, não conseguia penetrar o imaginário do povo sertanejo, sendo paulatinamente substituída pela xilogravura, que então se torna a verdadeira iconografia do fantástico. Ela retoma as temáticas tradicionais e o tom satírico e alegórico do cordel. Baneux explica que, ilustrando as capas de seus cordéis, os poetas prolongam suas narrativas e alimentam a intriga em torno de cada história.

A xilogravura seria o processo mais simples de reprodução de imagem. Sendo expressão acessível, com sua linguagem o público poderá guardar a lembrança de uma história que ele vai tornar sua (BANEUX, 2005, p. 18-19). 
Figura 3: Capa do folheto A chegada da

prostituta no Céu

Chartier, por sua vez, afirma que os textos impressos dependem dos dispositivos tipográficos para construção de seus sentidos, defendendo que a imagem da capa do folheto tem a função de imagem-símbolo em relação ao título, posto que fornece pistas sobre o sentido geral do texto (CHARTIER, 2002, p.180).

\section{O IMAGINÁRIO DE J. BORGES EM QUATRO XILOGRAVURAS}

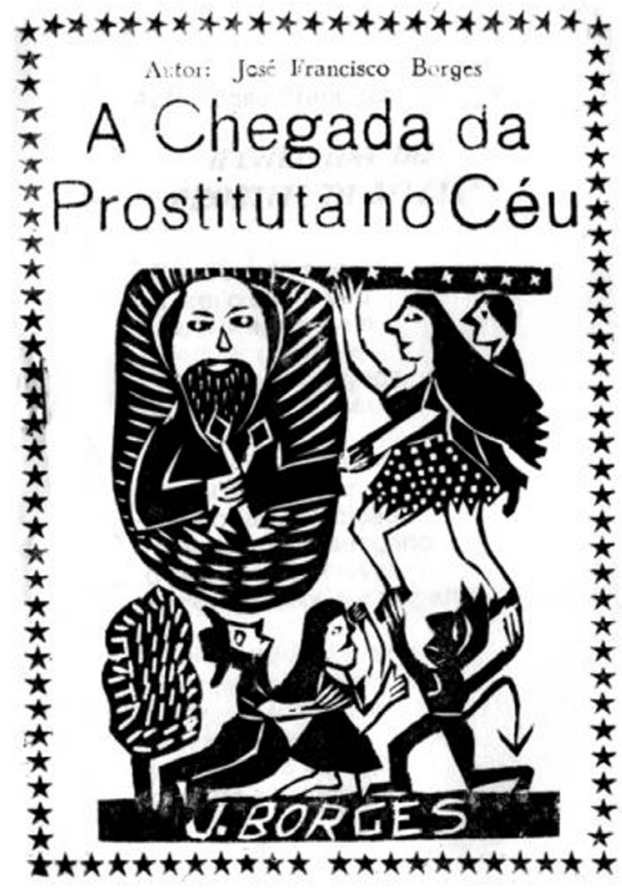

Nos traços do imaginário popular do Nordeste revelados pelas xilogravuras de J. Borges, os personagens oprimidos e excluídos dessa região, plena de contrastes sociais, encontram maneira de se transformar em heróis em um mundo mais harmônico e mágico. Nossa meta agora é desenvolver uma reflexão inspirada em modelos descritivos, tendo como fundamento os processos narrativos e expressivos, vendo nos primeiros as particularidades do universo icônico, seus personagens e cenários, enquanto os segundos revelam os valores plásticos, a textura e os componentes formais da imagem. Consideramos que esses dois processos estão intimamente intrincados e fazem parte de uma só trajetória, elaborada através de uma rede de signos e representações imaginárias plasmada em determinado universo cultural.

A primeira xilogravura analisada tem como título $A$ chegada $d a$ prostituta no Céu (Figura 2); realizada em 1976, é a preferida de J. Borges e também sua mais conhecida. As pessoas, intrigadas, sempre lhe pedem para descrever cada detalhe e explicar seu sentido ou sua moral. Curiosamente, essa xilogravura foi elaborada antes de a narrativa de cordel ser escrita. 0 sucesso foi surpreendente, e, diante da enorme demanda de pedidos, J. Borges precisou então escrever um cordel especialmente sobre ela (Figura 3). É muito raro uma xilogravura dar vida a uma narrativa de cordel, sendo o inverso o que geralmente ocorre. 
deve ser imperativamente enganado no final. Em depoimento a Clodo Ferreira, J. Borges explica:

Ele é muito atrativo, porque o povo todo teme o diabo. Não existe. Existe só o entendimento. E foi bom que existisse na mente do povo para amedrontar, senão a coisa ficava muito pior. No meu modo de pensar, não existe diabo. Existe só na ficção, mas ele amedronta todo mundo. Quando ele aparece é de uma forma que alguém se assusta. Mas tem que saber trabalhar e, dentro da escrita do cordel, fazer ele como inferior e dar um toque, maltratando ele (FERREIRA, 2006, p. 69).

Em A chegada da prostituta no Céu, o diabo tenta reter a prostituta para levá-la com ele, mas são Pedro tem poder superior. Notamos essa característica pelo tamanho de ambos - o santo é representado muito maior do que o diabo. A segunda personagem na parte de baixo da gravura é uma mulher que corre atrás da prostituta com uma faca na mão. É a mulher traída que, provavelmente, surpreendeu seu marido com a prostituta e a matou a golpe de faca. Enfurecida, ela continua a persegui-la mesmo após sua morte. Seu marido, que se encontra atrás, tenta detê-la. Em cima da imagem, à direita, atrás da prostituta, vemos um homem. É seu gigolô que prometeu sempre a seguir, aonde quer que ela fosse, céu ou inferno.

Segundo J. Borges, a prostituta é ser muito sacrificado e odiado pela sociedade e pelas mulheres casadas. Fazer essa xilogravura foi a maneira que ele encontrou de homenageá-la. Ele explica:

Eu acho que a prostituta é uma mulher que sofre muito, ela é marginalizada pela sociedade principalmente pela religião. Na minha época, ela era rigorosamente proibida de ir a missa, de se confessar e até mesmo de batizar um afilhado. Eu não estava de acordo com esta maneira de pensar, pois eu acho que ela é um ser humano como os outros (FERREIRA, 2006, p. 69).

A segunda xilogravura se intitula $O$ monstro do sertão (Figura 4), uma das mais impressionantes criações de J. Borges. Vemos um animal tendo o sol por cabeça e o corpo de boi; tem olhos grandes, e sua boca aberta expõe dentes pontudos e irregulares.Seu corpo é peludo, mas percebemos também a presença de escamas, como se o boi se tivesse transformado em dragão. Tratase de representação do sobrenatural, que nos remete às longínquas influências culturais e iconográficas do cordel, que se originam, em muitos aspectos, na Europa medieval.

J. Borges gosta de fazer xilogravuras com criaturas monstruosas, como dragões, serpentes enormes, animais com várias cabeças, seres híbridos, 


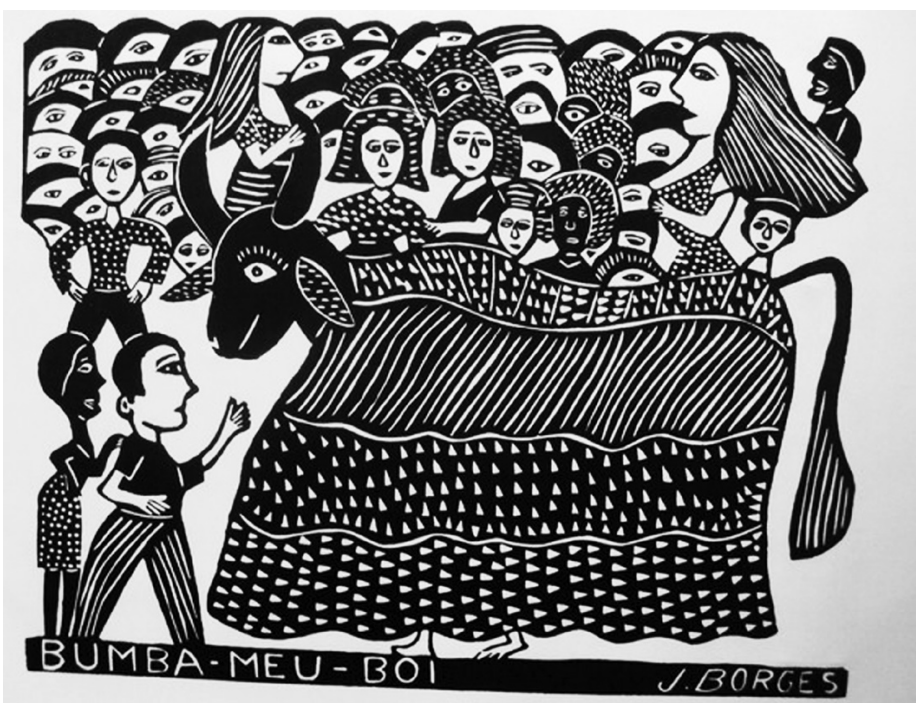

Figura 5:

J. Borges, Bumba meu boi, xilogravura

metade homem, metade animal. O de $O$ monstro do sertão, no entanto, não é um ser fantástico como os outros. É, de fato, um monstro bastante real para os habitantes do sertão, pois representa o sol que queima suas plantações, que mata suas crianças e seus animais, que os condena a deixar suas terras para encontrar outras, mais exploráveis. Esse monstro é a seca. A legenda versificada em cordel, na parte superior da gravura, resume o sentido que ela possui: a beleza feita pelo criador e que clareia o mundo é também o terror que acaba com a lavoura do agricultor.

Por outro lado, apresentar o corpo do monstro em forma de boi, é a revelação da importância desse animal no rico imaginário sertanejo. $\mathrm{Na}$ literatura oral nordestina, ele é aclamado por suas façanhas, força e destreza. Segundo Câmara Cascudo (2002, p. 69) “...o boi está de tal forma inserido no contexto cultural do Brasil que sua figura se apresenta em folguedos folclóricos, canções, literatura de cordel e tantas outras manifestações...".

A terceira xilogravura, Bumba meu boi (Figura 5), é a representação de uma dessas manifestações. Trata-se de dança ritualizada e praticada anualmente de novembro a janeiro como uma farândola musical e colorida. Muito popular em todo o Brasil, o bumba meu boi tem nomes e características diferentes conforme a região em que é praticado. É uma espécie de ópera popular que mistura dança e representação teatral, sendo o boi o personagem principal. Câmara Cascudo (2002, p. 69) afirma: “No Brasil este folguedo teve origem no ciclo econômico do gado, sendo produto de tríplice miscigenação, 


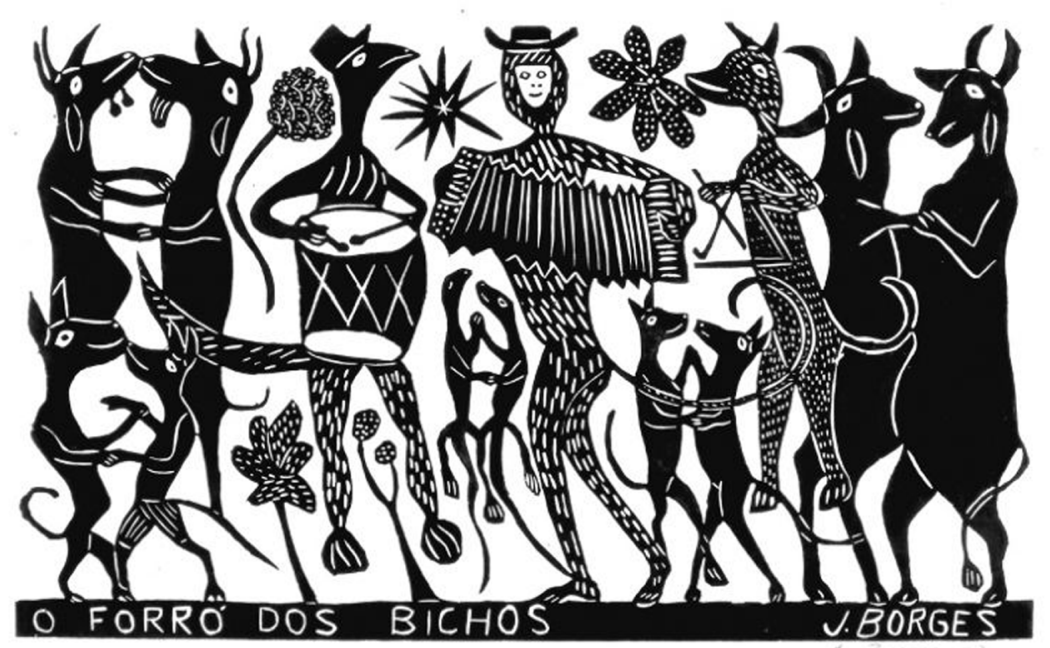

Figura 6: J. Borges, O forró dos bichos, xilogravura

com influência indígena, do negro escravo e do português. $O$ enredo desse folguedo apresenta uma série de variantes".

A variante mais conhecida no Nordeste conta que um rico fazendeiro possuía um belo boi que sabia dançar e que foi roubado por pai Francisco, um de seus empregados, cuja mulher, Catirina, uma escrava grávida queria comer a língua do animal. $O$ fazendeiro manda os vaqueiros e os índios procurarem seu boi predileto, que é encontrado doente em algumas versões ou morto em outras. Em seguida, o fazendeiro pede ajuda ao pajé que dança em volta do animal até ressuscitá-lo. No final, o fazendeiro perdoa pai Francisco e Catirina, e tudo termina em festa.

O boi é de madeira e decorado com tecidos ou papéis. Há também uma saia colorida para esconder o homem debaixo da armação e que a movimenta. $\mathrm{Na}$ xilogravura de J. Borges vemos apenas seus pés que ultrapassam o corpo do boi. Os outros personagens são apresentados de maneira alegórica, com roupas muito coloridas. As mulheres não participam da dança, e os personagens femininos são na realidade homens travestidos.

Na xilogravura de J. Borges reconhecemos os personagens pai Francisco e sua mulher, que estão representando o roubo do boi. Atrás, notamos o fazendeiro, que observa a cena, em gestualidade que revela posição de vigilância, mantendo as mãos na cintura. Em volta, o público canta e dança junto com os atores. Notamos que o tamanho das figuras que representam os espectadores não é igual - duas mulheres são muito maiores do que o restante 
da plateia, praticamente composta apenas de cabeças, muitas com apenas um olho.

A quarta e última xilogravura se intitula $O$ forró dos bichos (Figura 6) e representa a música e a dança mais populares do Nordeste. Vários ritmos brasileiros tipicamente nordestinos se misturam nessa dança que enfeitiça e seduz, como o baião, a quadrilha, o xaxado e o xote. Esses ritmos são influenciados pelas danças de salão europeias e principalmente pela chula, dança popular portuguesa ao som de instrumentos iguais aos do forró. Os textos falam de natureza e amor e ecoam a cultura sertaneja. Segundo Baneux, existiam no Nordeste:

formas de expressões poéticas, exclusivamente orais, vindas dos camponeses sertanejos, que se desenvolveram com os cantadores do século XIX. Esses cantores ocasionais eram frequentemente antigos escravos e exerciam seu talento nas festas populares, tornando-se pouco a pouco artistas reconhecidos. Eles inseriram em seus cantos uma dimensão poética versificada acrescentada de louvores para os convidados. Neles, misturam-se informações da atualidade e romances, finalizando a apresentação com improvisos. Essa mistura impetuosa se encontra nas múltiplas formas musicais nordestinas (BANEUX, 2005, p. 18).

Ainda que composto em molde diferente, o forró é hoje a emanação mais viva do falar nordestino, pois joga com essa poesia tradicional, mesmo sendo antes de tudo uma dança popular, muito presente, aliás, nas festas juninas. Os músicos são frequentemente reunidos em grupo de três e tocam acordeão, triângulo e zabumba. Segundo Câmara Cascudo (2002, p. 763): “O zabumba é o instrumento popular, predileto, inseparável, dos nossos sambas, batuques, maracatus, pastoris e zé-pereiras, constituindo como que a nota predominante, característica daqueles divertimentos populares".

Na gravura de J. Borges o macaco é o acordeonista, o tamanduá toca o zabumba, e o cachorro, o triângulo. Em volta deles dançam vários casais: o boi e a vaca, o bode e a cabra, os cães e as cadelas, e os lagartos. Muitos deles desafiam a gravidade e parecem estar flutuando na gravura, assim como as flores em volta. Essa é outra característica da arte naïf que, em seu discurso icônico e plástico, rompe com as diretrizes espaciais da pintura elaborada nos modelos canônicos do aprendizado acadêmico. As elaborações expressivas da arte naïf também estão presentes na livre interpretação das formas cromáticas.

Todos os animais que estão na xilogravura existem e fazem parte do imaginário do sertão. Sua humanização é muito comum nas xilogravuras e nas 
narrativas de cordel. Câmara Cascudo (1984, p. 20) explica: “O sertanejo ama a história dos bichos, macacos, camaleões, tamanduás, raposas, preás, vinte outros, falando, governando, discutindo, casando, brigando como homens. Esses romances de bichos têm efeito seguro no humorismo sertanejo".

As xilogravuras de J. Borges aqui abordadas revelam, através de suas estruturas temáticas e plásticas, representações de seres fantásticos que se misturam com as atividades lúdicas, como as festas populares. Tratase de um pequeno universo iconográfico, cuidadosamente construído com intenções ornamentais e decorativas. Nele, os espaços são indeterminados e a convivência entre a vida cotidiana e o sobrenatural não tem fronteiras rígidas, rompendo, portanto, os limites entre o sagrado e o profano. Esses fragmentos narrativos, construídos através de imagens fixas, expressam simbolicamente as relações sociais e culturais de determinadas camadas populares brasileiras profundamente enraizadas nas regiões rurais - um modo de vida ainda subsistente na era das grandes transformações provocadas pelas novas tecnologias de comunicação que dominam o mundo contemporâneo. Esses fragmentos narrativos também expressam os fundamentos de uma identidade brasileira complexa, rica e contraditória que é construída através de influências europeias, indígenas e africanas.

Não devemos, no entanto, esquecer que a identidade é de bastante difíceis delimitação e definição, precisamente em razão de seu caráter multidimensional e dinâmico, de modo particular em nossos tempos, considerados por Néstor García Canclini (1989) o das culturas híbridas. Essas culturas híbridas surgiram e se expandem no cenário de incertezas da modernidade tardia da América Latina, em que os cruzamentos socioculturais fazem o tradicional e o moderno se misturarem. Canclini estuda a introdução das novas tecnologias na complexidade urbana e moderna, bem como as consequências e transformações que elas desenvolvem nas microssociedades. 0 autor prefere chamar essa nova situação intercultural de hibridação em vez de sincretismo ou mestiçagem:

porque abrange diversas mesclas interculturais - não apenas as raciais, às quais costuma limitar-se o termo "mestiçagem" - e porque permite incluir as formas modernas de hibridação, melhor do que "sincretismo", fórmula que se refere quase sempre a fusões religiosas ou de movimentos simbólicos tradicionais (p. 19).

Portanto, a hibridização é processo de intercâmbios e misturas culturais. No que se refere à arte, cultura popular e cultura de massa, presenciamos complexo e fragmentário processo de interatividades. Os modelos únicos de 
análise são rompidos através de imagens e objetos com características híbridas em que não há mais apenas um elemento em questão. No Brasil, levandose em conta as proposições heterogêneas que são apresentadas por esse conceito, devemos considerar que as peculiaridades da miscigenação, aliadas à diversidade geográfica do país, são as características marcantes na construção da identidade - presente no imaginário dos indivíduos, sendo transmitida culturalmente nas artes, na música, na literatura, na tradição oral, na mídia e, de maneira acentuada, no folclore. É nesse sentido que compreendemos e apreciamos a obra de J. Borges, que contribui para estabelecer intrínseca relação entre o popular e o nacional na construção da identidade brasileira.

\section{REFERÊNCIAS BIBLIOGRÁFICAS}

BANEUX, Pascal. L'Homme qui racontait des histoires: gravures du sertão brésilien. Paris: Editions Alternatives, 2005.

CANCLINI, Néstor García. Culturas híbridas: estratégias para entrar e sair da modernidade. São Paulo: Edusp, 1989.

CHARTIER, Roger. A história cultural entre práticas e representações. Lisboa: Difel, 2002.

CASCUDO, Luís da Câmara. Vaqueiros e cantadores. São Paulo/Belo Horizonte: Editora Itatiaia, 1984.

. Dicionário do folclore brasileiro. São Paulo: Global Editora, 2002.

FERREIRA, Clodo (org.). J. Borges por J. Borges: gravura e cordel no Brasil. Brasília: Ed. UnB, 2006.

MICHELI, Mario de. As vanguardas históricas. São Paulo: Martins Fontes, 1991.

PEDROSA, Mário. Panorama da pintura moderna. In: . Arte, forma e personalidade. São Paulo: Kairós, 1979.

RIMBAUD, Arthur. Oeuvres complètes. Paris: Gallimard, 1972.

\section{NOTAS}

1 Bienheureux, j'allongeai les jambes sous la table: je contemplai les sujets très naïs de la tapisserie (RIMBAUD, 1972, p. 32-33).

2 Deve-se também acentuar a obra de Jorge Amado, que mergulha suas narrativas na riqueza da cultura baiana afro-brasileira, em que personagens originários do povo se tornam seus heróis, e a de Guimarães Rosa que, em Grandes Sertões: Veredas, narra o universo mítico do sertanejo mineiro. Mais tarde, nos anos 60, o cinema de Glauber Rocha, como em Deus e o Diabo na Terra do Sol, utilizará personagens e mitos populares que têm por cenário o Nordeste. Todas essas obras possuem tendência igual: unir o discurso nacional e o popular como forma de compreender a sociedade brasileira.

3 Hoje com 76 anos, ao lado de seus filhos, continua trabalhando em seu ateliê em Bezerros. Desde 2006, J. Borges é considerado Patrimônio Vivo de 
Pernambuco, título outorgado pelo governo do estado, tendo recebido também o prêmio Unesco na categoria Ação Educativa/Cultural. Em 2002, foi um dos 13 artistas escolhidos para ilustrar o calendário anual das Nações Unidas. O cordel é um jornal impresso em pequeno formato, com número de páginas que varia de oito a 40. De origem europeia, essas narrativas se tornam populares no século $\mathrm{XVI}$ através dos relatos dos trovadores medievais. Segundo Roger Chartier, é na Espanha e no século XVIII "que os pliegos de cordel encontram a sua forma clássica a de pequenos livros de uma ou duas folhas, e uma difusão maciça assegurada em parte pelos vendedores ambulantes cegos que cantam seus textos antes de os venderem" (CHARTIER, 2002, p. 165-166).

Laura Bitarelli Reboulet é doutoranda em literatura pela Universidade de Paris 3 - Sorbonne Nouvelle, onde prepara tese sobre a obra de J. Borges. É mestre em literatura pela mesma Universidade (2011) e licenciada em Letras pela Universidade do Estado do Rio de Janeiro - Uerj (2009). 
